\title{
Proposals of applications of tension-strut systems in building structures
}

\author{
Propozycje zastosowania układów prętowo-cięgnowych \\ w konstrukcjach budowlanych
}

JANUSZ RĘBIELAK *

DOI: https://doi.org/10.17814/mechanik.2017.7.79

Tension-strut systems belong to the most economic types of structural systems. Component parts are subjected to act only of compression forces or they are subjected to act only of tension forces. Suitable pre-stressing is the necessary condition of their proper operational use. Due to this feature they are of relatively big spatial stiffness and they require relatively small consumption of materials needed to their construction. They are mostly applied in bearing structures of hanging or suspension bridges and in support systems of the lightweight roof covers, particularly of big spans. Construction formula of the tension-strut systems is nowadays widely applied in structures of the large curtain walls, in support structures of multi-story buildings and it is proposed to use in the foundation structures. The paper presents some selected types of such structures worked out by the author for various useful purposes. Complexity of these structures requires application of appropriate numerical methods during processes of the design and of the assembly stage in the building site.

KEYWORDS: structural system, tension-strut structure, roof cover, foundation, numerical model

Weight of typical roof coverings made e.g. as standard beam or truss systems is an important part of the value of dead loads considered during the design process. As the clear span of cover increases, the dead weight share of this type of construction increases considerably [1-4]. Because the bending or compression elements have relatively large cross-sectional areas, their own masses must also be sufficiently large. Elements subjected to axial stretching require small cross sections to safely transmit such forces (even large values), so they are usually very lightweight. A structural system consisting solely of tension elements is therefore a lightweight and economical bearing system. The superstructures are considered to be most effective in the form of a minimum surface, which means that at every point of the structure located on such surface there are tensile forces having the same value in all directions [5]. Roofs designed with such construction systems often have a very interesting architectural form, but with a usable purpose, they cannot always be used. Striving to reduce the cost

\footnotetext{
* Prof. dr hab. inż. arch. Janusz Rębielak (j.rebielak@wp.pl) - Politechnika Krakowska, Wydział Architektury, Instytut Projektowania Budowlanego (A-4), Pracownia Konstrukcji Budowlanych (A-44)
}

of operating large enclosures with large cubature and roof rises has prompted designers to look for new types of dome systems that may have small heights [2, 6, 7]. D. Geiger's cable domes belong to a group of tensionstrut structures that can have extremely small roof rises. As lightweight construction systems, they are often used as roof support structures with large spans and are erected above circular or oval base projection forms.

\section{Crystalline tension-strut structure}

One of these types of constructions, developed by the author, is the crystal tension-strut structure [8, 9], the shaping steps of which are shown in fig. 1. The basis was the corresponding spherical form of the crystal space structure of the structure shown in fig. 1a-e.

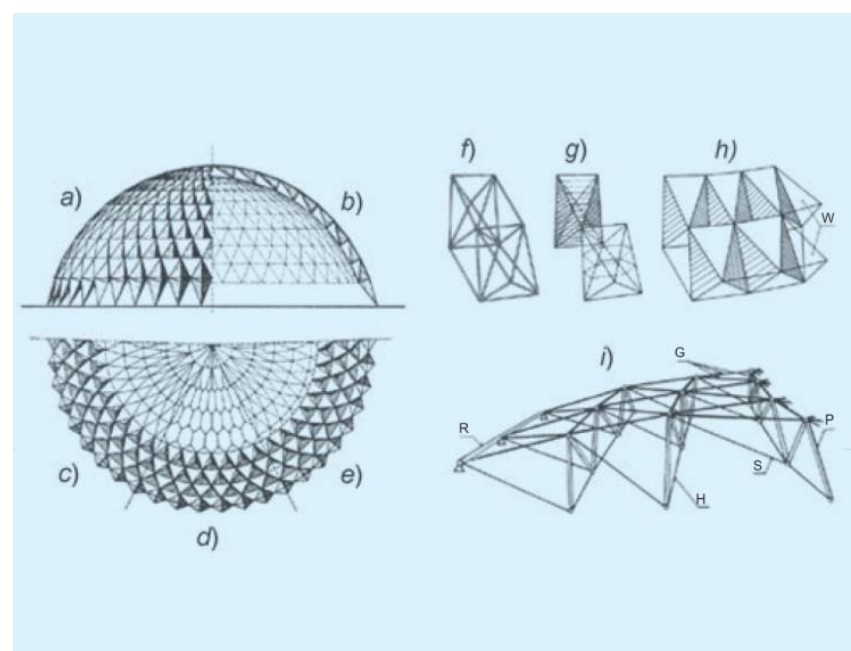

Fig. 1. Schemes for shaping a crystal tension-strut structure: a) fragment of the façade, b) fragment of a cross-section of a dome, c) top layer members, d) diagonal arrangement, e) top layer members, f) arrangement of rod modules, g) triangular panels, h) location of the window panels, i) structure of the crystal tension-strut structure

A scheme of a solid system of this structure, consisting of octahedral and tetrahedral modules, is shown in fig. 1f. The favorable lighting conditions of the interior of such a dome were obtained by arranging the light triangular panels on the corresponding walls of octagonal modules (fig. $1 \mathrm{~g}$ ) and window panels $(W)$ in every second triangular box of the outer spherical layer of members. The final form of the crystalline tension-strut structure was obtained by changing the status of most components and reducing the number of selected components (fig.1i). It has been assumed that most of 
the components will be the tension members, which in the upper layer $(G)$ forms a triangular network. The few struts $(P)$ are diagonally located in the concentric hoops $(H)$, which are also connected to each other by means of corresponding diagonal tension members $(S)$. The whole structure is connected to the support nodes by means of suitable tension members, which support nodes are uniformly arranged along the circumferential compression ring $(R)$. The physical model of the simplest form of such a system is shown in fig. $2 a$.
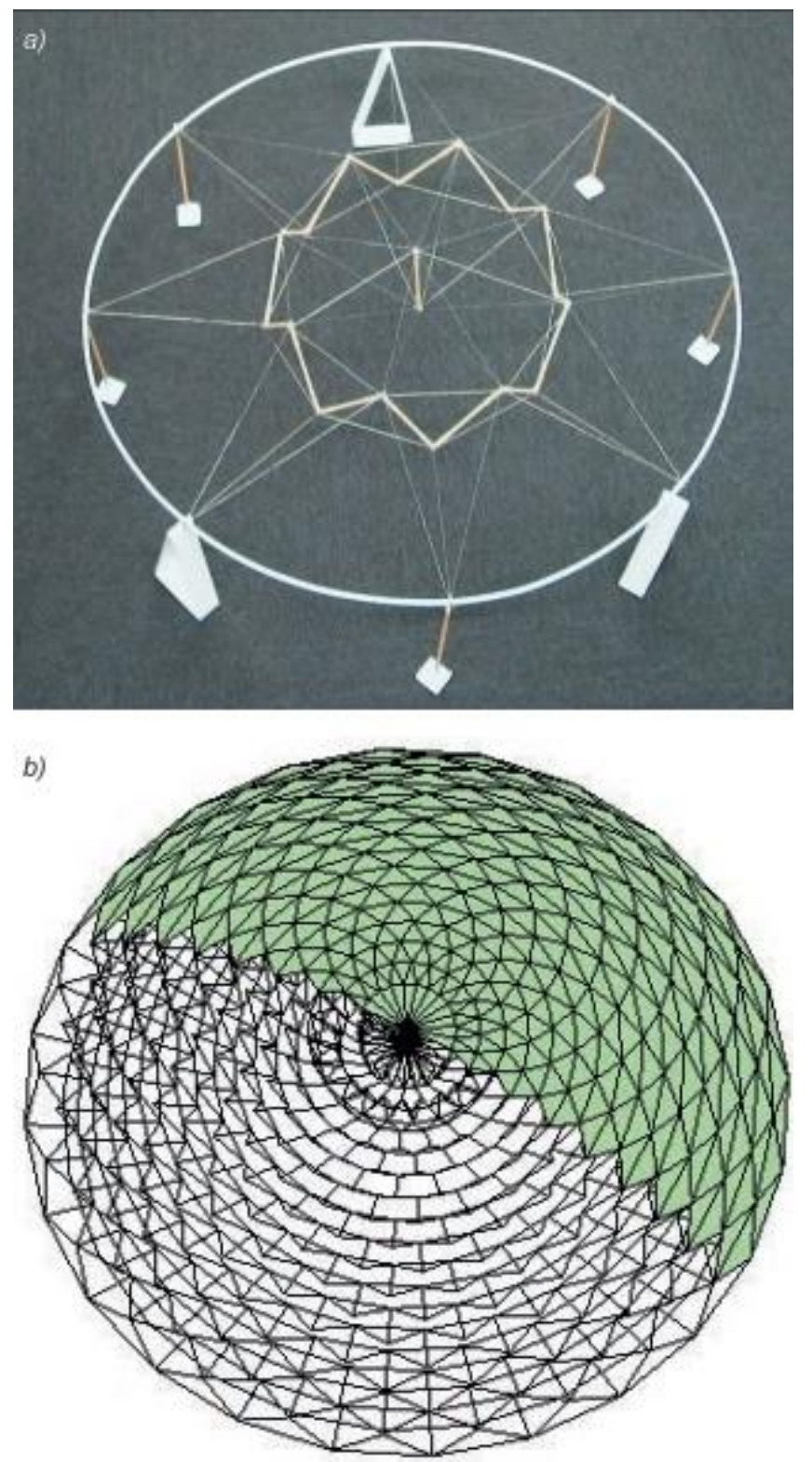

Fig. 2. Physical model of the simplest form of the crystal tensionstrut structure (a) and visualization of the numerical model of a more complex form of this structure (b)

Structures constructed in the proposed manner have greater spatial stability and are easier to assemble compared to typical Geiger dome domes. Systems designed for large-span cover structures must consist of at least several internal rings, and this requires the elaboration of a complex set of technical data - their preparation is greatly facilitated by the development of a suitable numerical model of the designed object. Next came the program content named ProgramQ, written in the Formian programming language [10]. This program defines the numerical model of the complex crystal tension-strut structure designed as a small dome-shaped domed structure over a circular view of a shape similar to that shown in fig. 1i. This part of the visualization shows the location of the diaphragms in the triangular fields of the top layer of the structure.

\section{ProgramQ}

01. $n=14 ;\left(^{*}\right)$ Parameter defining the number of divisions in the radial direction $\left(^{*}\right)$

02. $m=24 ;\left(^{*}\right)$ Geometrical parameter defining the number of divisions in the circumferential direction $\left(^{*}\right)$

03. $R=18 ;\left({ }^{*}\right)$ The radius of the top layer of the dome $\left(^{*}\right)$

04. $P P Z=[R, 0,0 ; R-1,0,0] ;\left(^{*}\right)$ Location of the vertical bar in the dome jumper $\left(^{*}\right)$

05. $P Z W=\operatorname{rin}(2, m, 2) \mid\{[R, 1,0 ; R, 1,1],[R-$

$1,0,0 ; R, 1,1],[R, 1,1 ; R-1,2,0]\}$;

06. $\mathrm{a}=\mathrm{PPZ \# PZW}$;

07. $P 1=\operatorname{lam}(2,1) \mid\{[R-1,0,1 ; R, 1,1],[R, 0,2 ; R, 1,1],[R-$

$1,0,1 ; R, 0,2],[R, 0,2 ; R-1,1,2]\} ;$

08. $P 2=\{[R-1,0,1 ; R-1,2,1],[R, 1,1 ; R, 3,1],[R, 0,2 ; R, 2,2],[R-$

$1,1,2 ; \mathrm{R}-1,3,2]\}$;

09. $\mathrm{PP} 1=\mathrm{P} 1 \# \mathrm{P} 2$;

10. $\mathrm{np}=\mathrm{n}+1$.

11. $\mathrm{n} 2=\mathrm{np} / 2$;

12. Band $1=\operatorname{rinit}(m, n 2,2,2) \mid P P 1$;

13. $\mathrm{DDA}=\operatorname{tran}(2,1)|\operatorname{tran}(3,1)| \mathrm{PP} 1$;

14. Band2=rinit(m,n2-1,2,2)|DDA;

15. EndRing $=\operatorname{tran}(3, n)|\operatorname{rin}(2, m, 2)|\{[R, 0,1 ; R, 1,2]$,

$[R, 1,2 ; R, 2,1],[R-1,1,1 ; R, 1,2]$,

$[R, 1,2 ; R, 3,2]\} ;$

16. $A=$ pex|PPZ\#PZW\#Band1\#Band2\#EndRing;

17. $\operatorname{Pan} 1=\{[R, 0,2 ; R, 1,1 ; R, 2,2],[R, 2,2 ; R, 3,1 ; R, 1,1]\}$;

18. Panel1=rinit $(m / 2, n 2,2,2) \mid$ Pan1;

19. $\operatorname{Pan} 2=\operatorname{ref}(3,2) \mid \operatorname{Pan} 1$;

20. Panel2=rinit $(m / 2, n 2-1,2,2) \mid P a n 2$;

21. $P a n e l 3=\operatorname{rin}(2, m / 2,2) \mid[R, 3,1 ; R, 1,1 ; R, 1,0] ;$

22. EndPanel $=\operatorname{tran}(3, n-1)|\operatorname{rin}(2, m / 2,2)|\{[R, 0,2 ; R, 1,3 ; R$,

2,2],[R,2,2;R,1,3;R,3,3]\};

23. Panel=Panel1\#Panel2\#Panel3\#EndPanel;

24. $B=P a n e l \# A$;

25. $S X P=b t(1,0.5,3) \mid B$;

26. DomeQ $=b s(1,360 / m, 5 / n) \mid S X P$;

27. use \&, vt(2), Iw(0.25), vm(2), c(1,1),c(3,39), vh(200,300,220,0,0,0,0,0,1);

28. draw DomeQ;

Using ordinal numbers for row ordering in an old version of Formian language was banned, but its recent release is recommended. Due to the use of selected parameters, the designer can adjust the shape of the structure to the changing design requirements, which greatly accelerates the design process and facilitates cooperation between the main participants in the entire investment process.

\section{Proposals of other forms of tension-strut structures}

Structural formula consisting of the assumed division of structural elements into ones which can take over only tensile or compressive forces presupposes the need to pre-compress the entire system. In order for the structure to meet the assumed assumptions, it is necessary to plan accordingly the positioning of the compressed and tension elements and the ways of connecting them. In the case of flat bar-tie systems, the task is relatively 
straightforward, but for spatial systems it usually gets complicated. It is helpful to analyze the arrangement of particular elements in selected forms of spatial modules. Rigid rods are placed within the adopted cubes of structural modules or on selected edges of such modules, which usually take the form of the simplest polyhedra - tetrahedron and octahedron. The specific type of built-in construction systems is referred to as the tensegrity, and their origin has been the work of $\mathrm{K}$. Snelson and R.B. Fuller [11, 12]. A defined group of such systems can be formed by means of spatial, tension-strut shaped strand structures consisting of tetrahedral modules (fig. 3a-b). These band structures are then placed parallel to the circumferential compression ring at increasingly higher levels (fig. $3 c-d$ ). The whole of this spatial structure is respectively pre-stressed and attached to the circumferential compression ring [13].
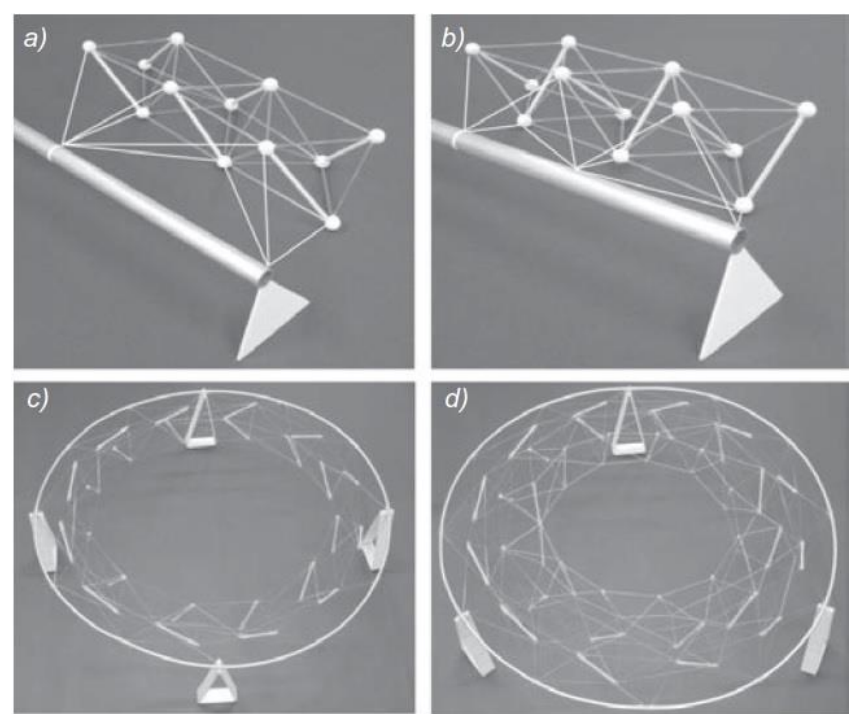

Fig. 3. Physical models of exemplary forms of tension-strut structures composed of concentric spatial rings

The structural concept of the tension-strut structure has been applied to components of the combined foundation system, called intermediate systems (fig. 4) [14]. Intermediate systems are so-called lenticular girders and are placed e.g. in narrow spaces between two parallel main beams (1).

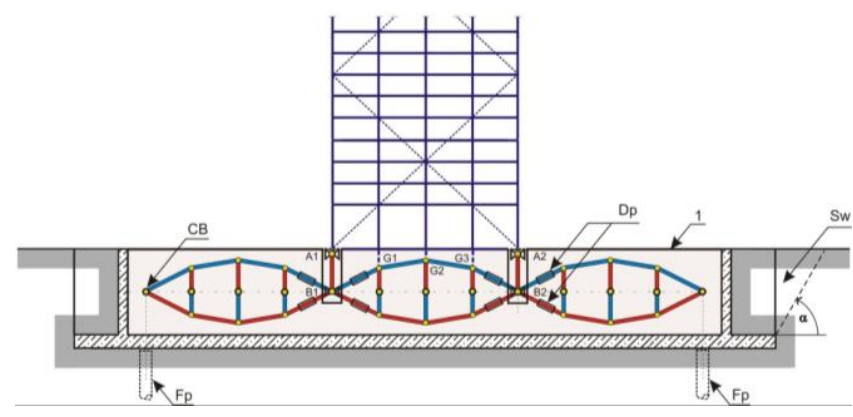

Fig. 4. Structural concept of the tension-strut structure applied to components of the combined foundation system

Thanks to the construction form of the lenticular girder, the composite foundation has the ability to damping vibrations caused by seismic effects. This feature can be strengthened by the placement of selected girder elements such as computer-controlled hydraulic jacks $(D p)$. The stability of the edge zones of the entire structure can be ensured by adequately compensating for the weight of the appropriate soil wedge or by using additional piles $(F p)$ designed directly below the edge nodes $(C B)$. Such a form of foundation will enable the foundation of objects heavily loaded on ground with low bearing capacity. The lenticular system shown in fig. 4 can be an inspiration for designing new and highly effective types of composite girders.

\section{Conclusions}

The tension-strut structures are now the most costeffective carrier systems for the use in architecture and engineering. They have a great flexibility in the shaping processes, which makes their development potential constantly assessed as very large, as can be seen in the examples given in this paper. The application of suitable numerical models of these sometimes very complex structural systems significantly facilitates the processes of their design, construction and subsequent operation.

\section{REFERENCES}

1. Makowski Z.S. "Analysis, design and construction of double-layer grids”. London: Applied Science Publishers, 1981.

2. Allen E., Zalewski W., Boston Structures Group. "Form and forces. Designing efficient, expressive structures". Hoboken, New Jersey: John Wiley \& Sons, 2010.

3. Berger $\mathrm{H}$. "Light structures - structures of light: the art and engineering of tensile architecture". Basel, Switzerland: Birkhäuser Verlag, 1996.

4. Schlaich J. "On some recent lightweight structures". Journal of the International Association for Shell and Spatial Structures. 43, 2 (2002): pages 69-79.

5. Otto F. "Natürliche Konstruktionen". Stuttgart: Deutsche VerlagsAnstalt, 1982.

6. Geiger D.H. "Roof structure". United States Patent, Patent No. 4,736,553., 12 April 1988.

7. Geiger D.H., Stefaniuk A., Chen D. "The design and construction of two cable domes for the Korean Olympics". Proceedings of the IASS Symposium on Shells, Membranes and Space Frames. Osaka, Japan, 1986, pages 265-272.

8. Rębielak J. "Simple form of structural system proposed for cable domes". Lightweight Structures in Civil Engineering. Local Seminar of IASS Polish Chapter, Warsaw-Wrocław, 7th December, 2001, pages $56-58$.

9. Rębielak J. "Shaping of space structures. Examples of applications of Formian in design of tension-strut systems". Wrocław: Oficyna Wydawnicza Politechniki Wrocławskiej, 2005.

10. Nooshin H., Disney P. "Formex configuration processing III". International Journal of Space Structures. 16, 1 (2001): pages $1-56$.

11. Snelson K. "Snelson on the tensegrity invention". International Journal of Space Structures. Special issue on Morphology and Architecture. Guest editor: H. Lalvani. 11, 1\&2 (1996): pages 43-48.

12. Fuller R.B. "Tensile-integrity structures". US Patent No. 3,063,521, November, 1962.

13. Rębielak J. "Basic groups of structural systems of cable domes shaped by means of tetrahedral modules". Lightweight Structures in Civil Engineering. Local Seminar of IASS Polish Chapter, WarsawWrockaw, 7th December, 2001, pages 64-67.

14. Rębielak J. "Proposals of application of system of combined foundation for buildings located in earthquake areas and in sea bays". Iranian Journal of Structural Engineering. 2, 1 (2015): pages 48-54. 